\title{
Fuzzy Analysis and Evaluation of Public Transport Service Quality: A Case Study of Dar es Salaam City, Tanzania
}

\author{
Erick P. Massami1 ${ }^{*}$, Benitha M. Myamba ${ }^{2}$, Leticia Edward ${ }^{3}$ \\ ${ }^{1}$ Unit for Applied Mathematics, Dar es Salaam Institute of Technology, Dar es Salaam, Tanzania \\ ${ }^{2}$ Department of Logistics and Transport Studies, National Institute of Transport, Dar es Salaam, Tanzania \\ ${ }^{3}$ Department of Computing and Communication Technologies, National Institute of Transport, Dar es Salaam, Tanzania \\ Email:^epmassami@hotmail.com, benitha9@yahoo.com, mihayoleticia@gmail.com
}

How to cite this paper: Massami, E.P., Myamba, B.M. and Edward, L. (2016) Fuzzy Analysis and Evaluation of Public Transport Service Quality: A Case Study of Dar es Salaam City, Tanzania. Journal of Transportation Technologies, 6, 297-311. http://dx.doi.org/10.4236/jtts.2016.65027

Received: July 27, 2016

Accepted: September 25, 2016

Published: September 28, 2016

Copyright $\odot 2016$ by authors and Scientific Research Publishing Inc. This work is licensed under the Creative Commons Attribution International License (CC BY 4.0).

http://creativecommons.org/licenses/by/4.0/ (c) (i) Open Access

\begin{abstract}
Urban public transport plays a critical role in stimulating economic development of any nation since most of the revenues come from cities. The majority of the city dwellers of any country use public transport. The evaluation of public transport service quality provides a valuable feedback to commuter operators to ensure continuous improvement of level of service and to the government to take appropriate measures for enhancing the quality of public transport service. This paper analyses and evaluates service quality of Road Public Transport (RPT) (i.e. minibuses and buses) and Urban Rail Transport (URT) in Dar es Salaam City, Tanzania. Since service quality and its attributes are intangible and vague, a fuzzy evaluation model is developed and applied. The formulated model is composed of Fuzzy Entropy Method (FEM) and Technique for Order Preference by Similarity to Ideal Solution (TOPSIS). The overall evaluation procedure is as follows: initially, an intensive literature search and experts' opinions are employed to establish criteria for evaluating the service quality of public transport in Dar es Salaam City. The developed FEM is used to obtain criteria weight. Lastly, the formulated TOPSIS is used to provide an overall ranking of urban public transport service quality. The overall evaluation shows that urban rail transport outperforms road public transport in terms of service quality. Nevertheless, the urban rail transport service in Dar es Salaam City is currently not well developed as it is provided on very limited routes. Thus, the Tanzania government, the rail transport operator i.e. Tanzania Railway Limited (TRL) and the agency responsible for the provision of rail infrastructure i.e. Reli Assets Holding Company (RAHCO) are advised to design and employ Public-Private-Partnership (PPP) schemes i.e. concession contracts to invest more in rolling stocks, locomotives and rail wagons so that the rail transport service is available on many routes of the
\end{abstract}


road public transport to bring fair competition between the two operators.

\section{Keywords}

Service Quality, Urban Public Transport, Entropy Method, Fuzzy TOPSIS, Dar es Salaam City

\section{Introduction}

Public transport plays a critical role in stimulating economic development of any nation. Majority of the population of any country use public transport. Transport differs from other challenges developing societies face as it gets worse rather better with economic development. While sanitation, education, and other challenges improve with economic growth, transport gets worse. An efficient transport system is crucial to a nation's development and can have far reaching benefits, and conversely, failing to do so will have an adverse repercussion on development. The rate of population growth in most developing countries is higher than the rate of car ownership, and therefore an increasing proportion of the population depends on public transport. Public transport also provides an alternative to private car owners who sometimes are deterred from using it by traffic congestion, parking difficulties or difficulties in accessing certain streets. In addition, most families of developing countries tend to be large, so that even if there is a car belonging to a household, most members of the family are still likely to use public transport for at least some of their travel. Thus, it is vital for the industry transport stakeholders to analyse and/or evaluate the public transport service quality to improve the standard of life. More specifically, evaluating the transport service level helps commuter operators understand their overall service quality in terms of manageable service attributes, thus identifying service areas to be improved with the index service as a service benchmarking and management tool. As such, service quality level has a very important significance for Transport Company's competitiveness in a free market. The government is also benefited from the efficient transport system which in turn stimulates the country's development. Nonetheless, most of the cities worldwide have been experiencing tremendous transport challenges including inadequacy of proper public transit service. In particular, Msigwa [1] identifies the challenges facing transportation in the cities of Tanzania. Massami and Myamba [2] evaluate the challenges facing public transportation in Dar es Salaam City, Tanzania in which the inadequacy of proper public transit service is identified as the second challenge.

Dar es Salaam City, being a Tanzanian financial and economic centre, plays a very big role for the development of the country as whole. In particular, Dar es Salaam sea port and the Dar es Salaam based Julius Nyerere International Airport (JINIA) are the main nodes for freight and passengers' supply chain in the international trade for Tanzanians and residents of the landlocked countries of Uganda, Rwanda, Burundi, East Democratic Republic of Congo, Zambia and Malawi. Thus, it is vital to measure the 
level of public transport service quality in Dar es Salaam City. Nonetheless, the evaluation of public transport service quality in the developing countries (e.g. Tanzania) is hardly investigated by the public transport operators and/or the government.

Traditionally, academicians and practitioners use SERVQUAL and SERVPERF for service quality evaluation. Although these studies address the ways of measuring the attributes' effectiveness, the imprecise nature of passenger's perception on service quality is not addressed [3].

Since service or level of service is considered an imprecise quantity, many researchers and practitioners are currently proposing models based on Fuzzy Set Theory (FST).

The paper is structured as follows: Section 2 presents a survey of previous work; modelling framework for urban public transport service quality is presented in Section 3; evaluation of public transport service quality in Dar es Salaam City is given in Section 4 and conclusions are presented in Section 5.

\section{Survey of Previous Work}

In recent years, service quality has become one of the most important issues in transport management [4]. Oña et al. [5] apply a cluster analysis technique for stratifying the sample of users of a public transport service in the city of Granada (Spain) in order to analyze passengers' opinions under more homogeneous conditions. Stelzer et al. [6] use a novel approach which uses standardised automated information exchange between travellers and Transportation Company tailored to improve the service quality of public transport. Mouwen [7] proposes a study to improve the understanding of the drivers of customer satisfaction with public transport (PT). D'Ovidio et al. [8] apply factor analysis with categorical principal component analysis and multivariate methods of classification to explore the characteristics of the customers and their quality perception on bus service of the town of Bari. Wang et al. [9] apply compound Poisson processes to formulate queues of batch arrivals and bulk service including balking and reneging behaviours of customers. Nicolás et al. [10] present a study aimed at providing the municipality of Alcoy-Spain with detailed information about public transport service based on functional, economic, social and spatial coverage. Bruglieri et al. [11] propose a study which focuses on the design and development of a real time mobility information system for the management of unexpected events, delays and service disruptions concerning public transportation in the city of Milan. Olsson et al. [12] measure the service experience in public transport using the Satisfaction with Travel Scale (STS). Khalid et al. [13] analyse data using SPSS to investigate user perceptions of rail public transport services (KTM Komuter) in Kuala Lumpur, Malaysia.

Song et al. [14] develop quantitative indicators for public transportation service evaluation and utilize data mining technique which derives data from the smart card system in the city of Seoul. Isabello et al. [15] review efficiency and effectiveness of interurban public transport services of the Piedmont region of Italy. Redman et al. [16] use a qualitative systematic review to better understand those aspects of public transport quality which most likely attract car users. Olio et al. [17] propose the methodol- 
ogy which provides the authorities and operating companies with useful information to plan personalised marketing policies at different categories of users and potential users of public transport. Daraio et al. [18] address the problem of efficiency and effectiveness of local public transport (LPT) with special emphasis on urban transit. Yaliniz et al. [19] evaluate the transit quality of service in Kutahya, Turkey based on aspects such as transit availability, comfort and convenience. Anna et al. [20] propose a panel data approach to analyze the passenger satisfaction of a public transport service. Lai and Chen [21] use passenger survey data from the Kaohsiung Mass Rapid Transit (KMRT) Taiwan and apply the structural equation modelling to explore the relationships between passenger behavioural intentions and the factors that affect them. Oña et al. [22] use data from a customer satisfaction survey collected by the transport consortium of Granada (Spain) apply a Structural Equation Model (SEM) to reveal the unobserved latent aspects describing bus transit service quality. Del Castillo and Benitez [23] apply models based on averages, multivariate discrete distribution and a generalized linear model to identify the aspects that mostly influence the perception of overall transport service quality.

In contrast to the most surveyed literature that employs statistical methods, very few studies employ soft computing techniques to evaluate transport service quality. Garrido et al. [24] propose Artificial Neural Networks (ANN) to analyze the service quality perceived by the passengers of Granada bus metropolitan transit system. Nonetheless, little attention is paid to evaluation of service quality in the Tanzanian urban transport environment. In addition, the evaluation of transport service quality is characterized by uncertainty, subjectivity, imprecision and ambiguity. Fuzzy set theory has been proven to be a useful mathematical tool for modelling uncertain i.e. imprecise and vague data in real situations [25].

Nowadays there are heaps of articles on the theory of fuzzy entropy and its application in weight determination. For instance, Gong et al. [26] use fuzzy entropy approach to determine the weights used to evaluate the reliability of emergency logistics system. Bray et al. [27] develop feature selection method based on fuzzy entropy and apply to a set of international container ports which is considered as Decision Making Units (DMUs). Lin and Tan [28] apply fuzzy entropy for weight determination in the evaluation of port development. On the other hand, fuzzy TOPSIS has been extensively applied for criteria assessment and ranking of alternatives in various fields. Behzadian et al. [29] provide useful insights of a state-of the-art survey of TOPSIS applications including supply chain management and logistics; design, engineering and manufacturing systems; business and marketing management, health, safety and environment management; human resources management; energy management; chemical engineering; water resources management and other topics. Awasthi et al. [30] propose a hybrid approach based on SERVQUAL and fuzzy TOPSIS for evaluating service quality of metro in Montreal. Torlak et al. [31] use fuzzy TOPSIS approach to evaluate business competition in the Turkish domestic airline industry. Awasthi et al. [32] present a multi-criteria decision making approach for selecting sustainable transportation sys- 
tems under partial or incomplete information (uncertainty). Toosi and Kohanali [33] use customer survey and apply AHP and fuzzy TOPSIS to evaluate service quality of three airlines in Qeshm free zone in Iran.

This study therefore presents a composite model of fuzzy entropy and fuzzy TOPSIS applied to evaluate transport service quality in Dar es Salaam City, Tanzania. The proposed approach has proven to be a powerful modelling tool for coping with subjectivity and imprecision in human judgements associated with service quality evaluation. The proposed composite model can provide transport operators and/or the government with valuable inputs on the analysis and evaluation of the level of transport service.

\section{Modelling Framework for Urban Public Transport Service Quality}

The fuzzy multi-criteria decision approach presented in this study is composed of two stages. The first stage describes the steps to obtain the evaluation performance for each criterion of the service quality while the second stage describes the steps to obtain the overall service quality of public transport.

\subsection{Evaluation of Performance Criteria}

Researchers and practitioners have proposed a number of methods for calculating the performance of criteria. These approaches are such as Analytical Hierarchy Process (AHP), Triangular Fuzzy Number (TFN), Fuzzy comparison method etc. In this study, Fuzzy Entropy Method (FEM) is used to obtain the performance of criteria. The FEM is a weight determination approach which gives the weight values of individual criteria and/or sub-criteria by calculating the entropy and entropy weight [34]. The larger the entropy, the smaller its entropy weight. When the entropy weight is zero, no useful information is provided to the decision-maker, and this criterion and/or sub-criterion can be removed from the process [35].

The following are the main steps of the FEM.

\subsubsection{Formation of the Standardized Evaluation Matrix}

The fuzzy evaluation matrix $R=\left[r_{i j}\right] \cdots i \in\{1,2, \cdots, I\}, j \in\{1,2, \cdots, J\}$ where $r_{i j} \in[0,1]$ is the membership grade of the $i^{\text {th }}$ criterion/sub-criterion to the $f^{\text {th }}$ evaluation level. This matrix $R$ is a result of accomplishment of the following steps.

\section{1) Formation of the Evaluation Set}

An evaluation set $V=\left\{v_{j}\right\}, j \in\{1,2, \cdots, J\}$ and $v_{j}$ stands for the $f^{\text {th }}$ evaluation level. This study proposes the evaluation set $V=\{$ Very dissatified, Not satisfied, Fair, Satisfied, Very satisfied $\}$.

\section{2) Determination of the Membership Grade}

The evaluators' scores are used to determine the membership grade of the evaluation set on each criterion. For instance, suppose there are $\mathrm{N}$ experts (i.e. evaluators) in which $x_{i j}(j=1,2,3, \cdots, J)$ experts believe that the influence of the criterion $i$ (e.g. 
convenience) belongs to the evaluation level $v_{j}, j \in\{1,2, \cdots, J\}$, then $r_{i j}=\frac{x_{i j}}{\sum_{j=1}^{J} x_{i j}}$ is the evaluation score. Thus, the single-factor evaluation matrix can be expressed by Equation (1):

$$
R=\left[\frac{x_{i j}}{\sum_{j=1}^{J} x_{i j}}\right], i \in\{1,2,3, \cdots, I\}, j \in\{1,2, \cdots, J\}
$$

\subsubsection{Weight Determination}

Suppose we have the standardized evaluation matrix $R=\left[r_{i j}\right]_{I J}$. Now the entropy of the $i^{\text {th }}$ criterion is defined by Equation (2):

$$
H_{m i}=-(\ln J)^{-1} \sum_{j=1}^{J} r_{i j} \ln \left(r_{i j}\right), m \in\{1,2,3, \cdots, M\}, i \in\{1,2,3, \cdots, I\}
$$

The weight of entropy of the $i^{\text {th }}$ criterion corresponding to alternative $m$ is defined by Equation (3):

$$
W_{m i}=\frac{1-H_{m i}}{I-\sum_{i=1}^{I} H_{m i}}, m \in\{1,2,3, \cdots, M\}, i \in\{1,2,3, \cdots, I\}
$$

where $0 \leq W_{m i} \leq 1$ and $\sum_{i=1}^{I} W_{m i}=1$.

\subsection{Fuzzy TOPSIS}

The TOPSIS method is proposed by Hwang and Yoon [36]. The fuzzy TOPSIS has proven to be an effective approach for ranking a finite number of alternatives characterized by multiple criteria [37]. This method defines the positive ideal solution (PIS) and the negative ideal solution (NIS). The PIS is the solution which gives the maximum benefit alternative and minimum cost alternative. Meanwhile the NIS is the one which gives the maximum cost alternative and minimum benefit alternative. The optimum value is the one which is closest to the PIS and farthest from the NIS. The general procedure for fuzzy TOPSIS starts by establishing the fuzzy decision matrix. This fuzzy decision matrix is used to deduce the normalized i.e. the weighted decision matrix. However, the elements of the weighted decision matrix are already given by the FEM. Consequently, the fuzzy TOPSIS modelling approach employed in this study involves the computation of the following:

The weighted (normalized) fuzzy decision matrix

The weighted fuzzy decision matrix is given by Equation (4)

$$
V=\left[v_{m i}\right]_{M I}, v_{m i}=w_{m i}, m \in\{1,2, \cdots, M\}, i \in\{1,2, \cdots, I\} .
$$

The fuzzy positive ideal solution (FPIS) and fuzzy negative ideal solution (FNIS) The FPIS of the alternatives is computed by Equation (5):

$$
A^{+}=\left(v_{1}^{+}, v_{2}^{+}, \cdots, v_{M}^{+}\right), v_{m}^{+}=\max _{m}\left\{v_{m i}\right\}, m \in\{1,2, \cdots, M\}, i \in\{1,2, \cdots, I\} .
$$

The FNIS of the alternatives is computed by Equation (6): 


$$
A^{-}=\left(v_{1}^{-}, v_{2}^{-}, \cdots, v_{M}^{-}\right), v_{m}^{-}=\min _{m}\left\{v_{m i}\right\}, m \in\{1,2, \cdots, M\}, i \in\{1,2, \cdots, I\} .
$$

\section{The distance of each alternative from FPIS and FNIS}

The distance $d_{m}^{+}$of $v_{m i}, m \in\{1,2, \cdots, M\}$ from the FPIS is computed by Equation (7):

$$
d_{m}^{+}=\sum_{i=1}^{I} d\left(v_{m i}, v_{m}^{+}\right)=\sqrt{\sum_{i=1}^{I}\left(v_{m i}-v_{m}^{+}\right)^{2}}, m \in\{1,2, \cdots, M\} .
$$

Moreover, the distance $d_{m}^{-}$of $v_{m i}, m \in\{1,2, \cdots, M\}$ from the FNIS is computed by Equation (8):

$$
d_{m}^{-}=\sum_{i=1}^{I} d\left(v_{m i}, v_{m}^{-}\right)=\sqrt{\sum_{i=1}^{I}\left(v_{m i}-v_{m}^{-}\right)^{2}}, m \in\{1,2, \cdots, M\}
$$

where $d(a, b)$ is the distance between two fuzzy numbers $a$ and $b$.

The closeness coefficient $\left(C C_{m}\right)$

The closeness coefficient of each alternative $\left(C C_{m}\right)$ is calculated by Equation (9).

$$
C C_{m}=\frac{d_{m}^{-}}{d_{m}^{-}+d_{m}^{+}}, m \in\{1,2, \cdots, M\}
$$

where $d_{m}^{-} \geq 0, \quad d_{m}^{+} \geq 0, C C_{m} \in[0,1]$. Thus, an alternative $m$ becomes closer to $A^{+}$as $C C_{m}$ approaches to 1 .

\section{Ranking of the alternatives}

The alternatives are ranked in decreasing order based on the values of the closeness coefficient $\left(C C_{m}\right)$. Thus, the most performing alternative is closest to the FPIS and farthest from the FNIS.

\section{Evaluation of Public Transport Service Quality in Dar es Salaam City}

The literature proposes numerous service attributes that influence the choice of public transport service. Currently there are two types of commuter services in Dar es Salaam City: Road Public Transport (RPT) composed of urban buses and mini-buses which operate on all legitimate routes and Urban Rail Transport (URT) which operate on very few routes with rail rolling stocks in place. This study therefore proposes only those attributes that are relevant to both commuter services (i.e. urban rail and urban buses/ min-buses). These service attributes are shown in Table 1.

\subsection{Data Collection Method}

A survey questionnaire was used to collect data from fifty (50) targeted respondents who gave their perceptions on the attributes of transport service quality. The sample of fifty (50) respondents has been considered based on the fact that the proposed fuzzy evaluation approach handles efficiently problems associated with vagueness and small data. In order to get useful inputs, the respondents chosen possessed at least a diploma qualification. We believe this kind of respondents could think critically and give unbiased assessments. In addition, the interviewer clarified the transport service attributes 
Table 1. Service standards of public transport in Dar es Salaam City.

\begin{tabular}{|c|c|c|}
\hline Code & Service Standard & Performance Measures \\
\hline \multirow{5}{*}{$C_{1}$} & \multirow{5}{*}{ Comfortability } & Type of seating, seat spacing, seat design and materials used \\
\hline & & The proportion of seated to standing passengers \\
\hline & & \\
\hline & & \\
\hline & & Luggage accommodation \\
\hline \multirow{3}{*}{$C_{2}$} & \multirow{3}{*}{ Security } & Pickpocketing on buses/trains and at bus stops and railroad stations \\
\hline & & Good lighting on buses/trains and at bus stops/train stations \\
\hline & & Presence of Conductors/Inspectors on the buses/trains \\
\hline \multirow{3}{*}{$C_{3}$} & \multirow{3}{*}{ Convenience } & Accessibility of bus stops/train stations in different parts of the city \\
\hline & & Frequency of service \\
\hline & & Interchangeability between services \\
\hline \multirow{4}{*}{$C_{4}$} & \multirow{4}{*}{ Safety } & Driving standards (i.e. Driving speed) \\
\hline & & Bus/train condition \\
\hline & & Overloading \\
\hline & & Road/Railway conditions \\
\hline \multirow{3}{*}{$C_{5}$} & \multirow{3}{*}{$\begin{array}{c}\text { Reliability and } \\
\text { Punctuality }\end{array}$} & Constant operation of a scheduled service \\
\hline & & Operation of service according to scheduled departure and arrival times \\
\hline & & Passenger complaints handling \\
\hline \multirow{3}{*}{$C_{6}$} & Attendants' & Courtesy of attendants \\
\hline & Interpersonal Skills & Helpful attitudes \\
\hline & & Smartness of attendants \\
\hline
\end{tabular}

and their components immediately before commencing the assessment exercise. Moreover, the purposive sample composed of respondents who often use both Road Public Transport (RPT) and Urban Rail Transport (URT).

\subsection{The Weights of Evaluation Criteria}

After analysing the collected data we get the following:

The standardised evaluation matrix for the road public transport service $\left(R_{1}\right)$ is given by Equation (10):

$$
R_{1}=\frac{1}{50}\left[\begin{array}{lllll}
17 & 22 & 10 & 1 & 0 \\
25 & 16 & 9 & 0 & 0 \\
3 & 16 & 20 & 11 & 0 \\
9 & 29 & 10 & 2 & 0 \\
4 & 21 & 19 & 6 & 0 \\
19 & 17 & 11 & 3 & 0
\end{array}\right] .
$$


Thus,

$$
R_{1}=\left[\begin{array}{lllll}
0.34 & 0.44 & 0.20 & 0.02 & 0.00 \\
0.50 & 0.32 & 0.18 & 0.00 & 0.00 \\
0.06 & 0.32 & 0.40 & 0.22 & 0.00 \\
0.18 & 0.58 & 0.20 & 0.04 & 0.00 \\
0.08 & 0.42 & 0.38 & 0.12 & 0.00 \\
0.38 & 0.34 & 0.22 & 0.06 & 0.00
\end{array}\right] .
$$

The standardized evaluation matrix for the urban rail transport service $\left(R_{R}\right)$ is given by Equation (12):

$$
R_{2}=\frac{1}{50}\left[\begin{array}{lllll}
2 & 11 & 19 & 12 & 5 \\
3 & 12 & 27 & 7 & 1 \\
13 & 21 & 13 & 3 & 0 \\
1 & 8 & 28 & 12 & 1 \\
8 & 14 & 16 & 9 & 3 \\
2 & 16 & 23 & 8 & 1
\end{array}\right]
$$

Thus,

$$
R_{2}=\left[\begin{array}{lllll}
0.04 & 0.22 & 0.38 & 0.26 & 0.10 \\
0.06 & 0.24 & 0.54 & 0.14 & 0.02 \\
0.26 & 0.42 & 0.26 & 0.06 & 0.00 \\
0.02 & 0.16 & 0.56 & 0.24 & 0.02 \\
0.16 & 0.28 & 0.32 & 0.18 & 0.06 \\
0.04 & 0.32 & 0.46 & 0.16 & 0.02
\end{array}\right] .
$$

We apply Equations (2) and (3) to compute the entropy and weight of each criterion for RPT and URT using the elements of the two standardized matrices given by Equations (11) and (13). The perception of passengers on service attributes for each of the transport service category is revealed in the ranking deduced from the calculated entropies and weights as shown in Table 2.

Table 2. Entropy, weight and rank of criteria for RPT and URT.

\begin{tabular}{ccccccc}
\hline Criterion $\left(C_{i}\right)$ & $H_{1 i}$ & $W_{1 i}$ & $R_{1 i}$ & $H_{2 i}$ & $W_{2 i}$ & $R_{2 i}$ \\
\hline$C_{1}$ & 0.701 & 0.173 & 3 & 0.876 & 0.101 & 5 \\
$C_{2}$ & 0.634 & 0.212 & 1 & 0.744 & 0.207 & 2 \\
$C_{3}$ & 0.766 & 0.136 & 5 & 0.766 & 0.190 & 4 \\
$C_{4}$ & 0.668 & 0.192 & 2 & 0.694 & 0.248 & 1 \\
$C_{5}$ & 0.738 & 0.152 & 4 & 0.927 & 0.059 & 6 \\
$C_{6}$ & 0.768 & 0.135 & 6 & 0.759 & 0.195 & 3 \\
\hline
\end{tabular}

Note: $H_{1: \dot{r}}$ criterion entropy for RPT; $H_{2 i}$ criterion entropy for URT; $W_{1 \dot{r}}$ criterion weight for RPT; $W_{2 \dot{r}}$ criterion weight for URT, $R_{m i}$ rank of criterion $i$ corresponding to alternative $m$. 
From Table 2, it is found that the customers i.e. passengers perceive the service quality of urban road transport in the order given in the set \{Security, Safety, Comfortability, Reliability and Punctuality, Convenience, Attendants' interpersonal skills\}. Thus, the passengers who use road transport in Dar es Salaam city are less concerned about the security, safety and comfortability aspects of the service and more concerned about the attendants' interpersonal skills, convenience, reliability and punctuality of the service. The findings suggest that the urban road transport operators can attract more passengers provided the following are done: Bus conductors and drivers are well trained and adhere to the professional code of conduct, operate scheduled services and increase the frequency of service.

On the other hand, the passengers perceive the service quality of urban rail transport in the order given in the set \{Safety, Security, Attendants' interpersonal skills, Convenience, Comfortability, Reliability and Punctuality\}. Thus, the passengers who use urban rail transport are less concerned about the safety and security attributes of the urban rail transport service and more concerned about the reliability and comfortability attributes. These findings require the rail transport operators to make sure there is a constant operation of a scheduled service and increase the frequency of service which in turn would decrease the proportion of seated to standing passengers in order to be more competitive in the public transport market.

Nonetheless, the RPT relatively outperforms the URT on the following attributes of service quality: reliability and punctuality, security and comfortability whereas the URT relatively outperforms the RPT on the following attributes of service quality: safety, attendants' interpersonal skills and convenience.

In order to win the urban public transport market, each operator needs to improve each service attribute over its competitor and formulate effective marketing strategies. The role of the government in this regard should be to formulate attractive policies to the investors and enforce the regulations effectively.

\subsection{Ranking of Urban Road Transport and Urban Rail Transport}

The fuzzy TOPSIS is applied to obtain the overall ranking of transport service quality by computing the following:

\section{The Weighted Fuzzy Decision Matrix}

The elements of the weighted fuzzy decision matrix $(V)$ are obtained by applying Equation (4).

$$
V=\left[\begin{array}{llllll}
0.173 & 0.212 & 0.136 & 0.192 & 0.152 & 0.135 \\
0.101 & 0.207 & 0.190 & 0.248 & 0.059 & 0.195
\end{array}\right]
$$

The Fuzzy Positive Ideal Solution (FPIS) and Fuzzy Negative Ideal Solution (FNIS)

Equation (5) is applied to obtain the FPIS:

$$
A^{+}=\left(V_{1}^{+}, V_{2}^{+}\right)=(0.212,0.248) \text {. }
$$

The fuzzy negative ideal solution (FNIS) is calculated by using Equation (6): 


$$
A^{-}=\left(V_{1}^{-}, V_{2}^{-}\right)=(0.135,0.059) \text {. }
$$

\section{The Distance of the Alternative from the FPIS and FNIS}

Equations (7) and (8) are respectively applied to get the distance of the alternative from the FPIS and FNIS as follows:

$$
\begin{aligned}
& d_{1}^{+}=\sqrt{\sum_{i=1}^{6}\left(V_{1 i}-V_{1}^{+}\right)^{2}}=0.131 \\
& d_{2}^{+}=\sqrt{\sum_{i=1}^{6}\left(V_{2 i}-V_{2}^{+}\right)^{2}}=0.255 \\
& d_{1}^{-}=\sqrt{\sum_{i=1}^{6}\left(V_{1 i}-V_{1}^{-}\right)^{2}}=0.104 \\
& d_{2}^{-}=\sqrt{\sum_{i=1}^{6}\left(V_{2 i}-V_{2}^{-}\right)^{2}}=0.308 .
\end{aligned}
$$

\section{The Closeness Coefficient $\left(\mathrm{CC}_{\mathrm{m}}\right)$}

The closeness coefficient for the Road Public Transport (RPT) is given by Equation (9):

$$
C C_{1}=\frac{d_{1}^{-}}{d_{1}^{-}+d_{1}^{+}}=\frac{0.104}{0.104+0.131}=0.443 .
$$

For the Urban Rail Transport (URT), the closeness coefficient is given by Equation (9):

$$
C C_{2}=\frac{d_{2}^{-}}{d_{2}^{-}+d_{2}^{+}}=\frac{0.308}{0.308+0.255}=0.547
$$

As $C C_{2}=0.547>C C_{1}=0.443$, the overall ranking of urban transport service in Dar es Salaam show that the urban rail service offers passengers, the service of relatively high quality. Nevertheless, the service comparison is not involving the newly operated Dar es Salaam Rapid Transit (DART) service which is offered on very limited routes. It should also be noted that the urban rail transport service in Dar es Salaam city is not well developed as it is provided on very few routes. From the analysis the following observations are revealed:

1) The government, the urban road transport and rail transport operators have the obligation of improving the urban transport service to meet the expectation of the current and potential passengers.

2) The rail transport operator, Tanzania Railway Ltd (TRL); the government agency responsible for the provision of rail infrastructure, Reli Assets Holding Company (RAHCO); and the government need to invest more into this transport service segment to meet the current and projected passengers' demand. More specifically, they have to invest more in rolling stocks, locomotives and rail wagons so that the services are available on many routes of the road public transport to bring fair competition between the two operators. As the government is constrained with financial resources, the expansion of the rail transport service can be achieved by involving the private sector through Public-Private Partnerships (PPPs). There are various schemes i.e. concession contracts available in the market such as Build-own-operate-transfer (BOOT), Build- 
own-operate (BOO), Build-own-transfer (BOT), Equip-operate-transfer (EOT) and Buildtransfer-operate (BTO).

3) The overall quality of service offered by the urban transport operators in the Dar es Salaam city has yet met the passengers' expectation. Thus, both urban transport operators should enhance their transport services.

4) The expected transport service quality in the Dar es Salaam city is hardly attained unless; the rail transport operators offer the service on all legitimate routes of the road transport service. This would create fair competition between the two transport operators and curb the envisaged monopolistic practices of the RPT. Nonetheless, Investment in commuter rail transit is a world-wide phenomenon, driven by the belief in its benefits, such as less congestion, less air pollution, improved labour market for the poor, and higher productivity in industries that make substantial use of vehicles in their production processes [38]. More specifically, if the rail transit is developed, it would slow down the rapid increase in auto use which in turn would benefit not only the local residents, but also the rest of the world affected by the massive greenhouse gas emissions from the road transport.

\section{Conclusion}

In this paper, a composite model of fuzzy entropy and fuzzy TOPSIS is proposed to analyse and evaluate the quality of transport service in Dar es Salaam City, Tanzania. The findings reveal that the overall service quality of urban transport is yet satisfactory i.e. the rail transport service is available during peak hours (morning and evening rush hours) excluding Sundays and public holidays meanwhile the road public transport, with the exception of Dar es Salaam Rapid Transit (DART), has contributed to high levels of congestion which in turn generates economic losses through wasted time, higher travel costs, poor road safety, and high levels of vehicle emissions. The evaluation results reveal that the rail transport service outperforms the road public transport service. In addition, the evaluation procedure generalises the application of fuzzy model to problems involving vagueness. Thus, the results can be an impetus to the transport operators and the government to take needful measures which include minimizing vehicle operating costs and formulating investment policies which will attract the private sector participation through designing various concession contracts. Nonetheless, the Tanzania government has started to implement the PPP scheme by completing the first phase of a six-phase Bus Rapid Transit (BRT) system. Since BRT is operated on very few routes of Dar es Salaam City, the public transit service is very limited. It should be noted that the magnitude of financial assistance needed for urban transport in Dar es Salaam as well as the rest of the country cannot just rely on development partners as the requirements significantly exceed their country allocations. The government needs to examine alternative sources of financing from local sources such as rates and taxes on property and land values. The proposed fuzzy model is recommended as an evaluation tool to other problems involving vagueness and scarcity of data. The future direction of this study is the analysis of the efficiency of the proposed concession contracts as a tool 
for funding the city's transport system to identify the most suitable PPP schemes in the Tanzanian environment.

\section{Acknowledgements}

We are very grateful for all respondents who participated in the data collection exercise.

\section{References}

[1] Msigwa, R.E. (2013) Challenges Facing Urban Transportation in Tanzania. Mathematical Theory and Modeling, 3, 18-26.

[2] Massami, E.P. and Myamba, B.M. (2016) Application of Vague Analytical Hierarchy Process to Prioritize the Challenges Facing Public Transportation in Dar es Salaam CityTanzania. International Journal of Advanced Research in Artificial Intelligence, 5, 46-53.

[3] Yeh, C.H. and Kuo, Y.L. (2003) Evaluating Passenger Services of Asia-Pacific International Airports. Transportation Research Part E, 39, 35-48. http://dx.doi.org/10.1016/S1366-5545(02)00017-0

[4] Lazim, A. and Wahab, N. (2010) A Fuzzy Decision Making Approach in Evaluating Ferry Service Quality. Management Research and Practice, 2, 94-107.

[5] Oña, R., López, G., Rios, F.J.D. and Oña, J. (2014) Cluster Analysis for Diminishing Heterogeneous Opinions of Service Quality Public Transport Passengers. Procedia-Social and Behavioral Sciences, 162, 459-466. http://dx.doi.org/10.1016/j.sbspro.2014.12.227

[6] Stelzer, A., Englert, F., Hörold, S. and Mayas, C. (2016) Improving Service Quality in Public Transportation Systems Using Automated Customer Feedback. Transportation Research Part E: Logistics and Transportation Review, 89, 259-271. http://dx.doi.org/10.1016/j.tre.2015.05.010

[7] Mouwen, A. (2015) Drivers of Customer Satisfaction with Public Transport Services. Transportation Research Part A: Policy and Practice, 78, 1-20. http://dx.doi.org/10.1016/j.tra.2015.05.005

[8] D’Ovidio, F.D., Leogrande, D., Mancarella, Schinzano, A. and Viola, D. (2014) A Multivariate Analysis of the Quality of Public Transport Services. Procedia-Economics and Finance, 17, 238-247. http://dx.doi.org/10.1016/S2212-5671(14)00868-5

[9] Wang, Y., Guo, J., Ceder, A., Currie, G., Dong, W. and Yuan, H. (2014) Waiting for Public Transport Services: Queueing Analysis with Balking and Reneging Behaviours of Impatient Passengers. Transportation Research Part B: Methodological, 63, 53-76. http://dx.doi.org/10.1016/j.trb.2014.02.004

[10] Nicolás, D.S., Colomer, O., Fiore, M. and Colomer, J.V. (2014) Restructuring of Public Transport Service of Alcoy. Procedia-Social and Behavioral Sciences, 160, 410-419. http://dx.doi.org/10.1016/j.sbspro.2014.12.153

[11] Bruglieri, M., Colorni, A., Luè, A., Bruschi, F., Rana, V. and Nocerino, R. (2015) A RealTime Information System for Public Transport in Case of Delays and Service Disruptions. Transportation Research Procedia, 10, 493-502. http://dx.doi.org/10.1016/j.trpro.2015.09.003

[12] Olsson, L.E., Friman, M., Pareigis, J. and Edvardsson, B. (2012) Measuring Service Experience: Applying The Satisfaction with Travel Scale in Public Transport. Journal of Retailing and Consumer Services, 19, 413-418. http://dx.doi.org/10.1016/j.jretconser.2012.04.002

[13] Khalid, U.A., Bachok, S., Osman, M.M. and Ibrahim, M. (2014) User Perceptions of Rail Public Transport Services in Kuala Lumpur, Malaysia: KTM Komuter. Procedia-Social 
and Behavioral Sciences, 153, 566-573. http://dx.doi.org/10.1016/j.sbspro.2014.10.089

[14] Song, J., Eom, J.K., Lee, K.S., Min, J.H. and Yang, K.Y. (2015) Public Transportation Service Evaluations Utilizing Seoul Transportation Card Data. Procedia-Computer Science, 52, 178-185. http://dx.doi.org/10.1016/j.procs.2015.05.053

[15] Isabello, A., Pensa, S., Arnone, M. and Rosa, A. (2014) Reviewing Efficiency and Effectiveness of Interurban Public Transport Services: A Practical Experience. Transportation Research Procedia, 1, 243-252. http://dx.doi.org/10.1016/j.trpro.2014.07.024

[16] Redman, L., Friman, M., Gãrling, T. and Hartig, T. (2013) Quality Attributes of Public Transport that Attract Car Users: A Research Review. Transport Policy, 25, 119-127. http://dx.doi.org/10.1016/j.tranpol.2012.11.005

[17] dell'Olio, L., Ibeas, A. and Cecin, P. (2011) The Quality of Service Desired by Public Transport Users. Transport Policy, 18, 217-227. http://dx.doi.org/10.1016/j.tranpol.2010.08.005

[18] Daraio, C., Diana, M., Di Costa, F., Leporelli, C., Matteucci, G. and Nastasi, A. (2015) Efficiency and Effectiveness in the Urban Public Transport Sector: A Critical Review with Directions for Future Research. European Journal of Operational Research, 248, 1-20. http://dx.doi.org/10.1016/j.ejor.2015.05.059

[19] Yaliniz, P., Bilgic, S., Vitosoglu, Y. and Turan, C. (2011) Evaluation of Urban Public Transportation Efficiency in Kutahya, Turkey. Procedia-Social and Behavioral Sciences, 20, 885-895. http://dx.doi.org/10.1016/j.sbspro.2011.08.097

[20] Anna, C., Antonello, D. and Angelo, P. (2014) A Panel Data Approach to Evaluate the Passenger Satisfaction of a Public Transport Service. Procedia Economics and Finance, 17, 231 237. http://dx.doi.org/10.1016/S2212-5671(14)00708-4

[21] Lai, W.-T. and Chen, C.-F. (2011) Behavioral Intentions of Public Transit Passengers-The Roles of Service Quality, Perceived Value, Satisfaction and Involvement. Transport Policy, 18, 318-325. http://dx.doi.org/10.1016/j.tranpol.2010.09.003

[22] de Oña, J., de Oña, R., Eboli, L. and Mazzulla, G. (2013) Perceived Service Quality in Bus Transit Service: A Structural Equation Approach. Transport Policy, 29, 219-226. http://dx.doi.org/10.1016/j.tranpol.2013.07.001

[23] Del Castillo, J.M. and Benitez, F.G. (2012) A Methodology for Modelling and Identifying Users Satisfaction Issues in Public Transport Systems Based on Users Surveys. ProcediaSocial and Behavioral Sciences, 54, 1104-1114. http://dx.doi.org/10.1016/j.sbspro.2012.09.825

[24] Garrido, C., de Oña, R. and de Oña, J. (2014) Neural Networks for Analyzing Service Quality in Public Transportation. Expert Systems with Applications, 41, 6830-6838. http://dx.doi.org/10.1016/j.eswa.2014.04.045

[25] Massami, E.P. and Myamba, B.M. (2014) Evaluation of Road Traffic Accident Risk Based on Fuzzy Set Theory. International Journal of Emerging Technology and Advanced Engineering, 4, 724-731.

[26] Gong, B., Chen, X. and Hu, C. (2012) Fuzzy Entropy Clustering Approach to Evaluate the Reliability of Emergency Logistics System. Energy Procedia, 16, 278-283. http://dx.doi.org/10.1016/j.egypro.2012.01.046

[27] Bray, S., Caggiani, L., Dell'Orco, M. and Ottomanelli, M. (2014) Features Selection Based on Fuzzy Entropy for Data Envelopment Analysis Applied to Transport Systems. Transportation Research Procedia, 3, 602-610. http://dx.doi.org/10.1016/j.trpro.2014.10.039

[28] Lin, R. and Tan, J. (2013) Evaluation of Port Development Based on the Theory of Driving Force and the Law of Entropy Weight. Procedia-Social and Behavioral Sciences, 96, 17741783. http://dx.doi.org/10.1016/j.sbspro.2013.08.202 
[29] Behzadian, M., Otaghsara, S.K., Yazdani, M. and Ignatius, J. (2012) A State-of the-Art Survey of TOPSIS Applications. Expert Systems with Applications, 39, 13051-13069. http://dx.doi.org/10.1016/j.eswa.2012.05.056

[30] Awasthi, A., Chauhan, S.S., Omrani, H. and Panahi, A. (2011) A Hybrid Approach Based on SERVQUAL and Fuzzy TOPSIS for Evaluating Transportation Service Quality. Computers \& Industrial Engineering, 61, 637-646. http://dx.doi.org/10.1016/j.cie.2011.04.019

[31] Torlak, G., Sanal, M., Zain, S. and Sevkli, M. (2011) Analyzing Business Competition by Using Fuzzy TOPSIS Method: An Example of Turkish Domestic Airline Industry. Expert Systems with Applications, 38, 3396-3406. http://dx.doi.org/10.1016/j.eswa.2010.08.125

[32] Awasthi, A., Chauhan, S.S. and Omrani, H. (2011) Application of Fuzzy TOPSIS in Evaluating Sustainable Transportation Systems. Expert Systems with Applications, 38, 1227012280. http://dx.doi.org/10.1016/j.eswa.2011.04.005

[33] Toosi, N.M. and Kohanali, R.A. (2011) The Study of Airline Service Quality in the Qeshm Free Zone by Fuzzy Logic. The Journal of Mathematics and Computer Science, 2, 171-183.

[34] Lin, Z.Z. and Wen, F.S. (2009) Entropy Weight Based Decision-Making Theory and Its Application to Black-Start Decision-Making. Proceedings of the CSU-EPSA, 21, 26-33.

[35] Jing, L.P. and Michael, K.N. (2009) An Entropy Weighting K-Means Algorithm for Subspace Clustering of High-Dimensional Sparse Data. IEEE Transactions on Knowledge and Data Engineering, 19, 1026-1041. http://dx.doi.org/10.1109/TKDE.2007.1048

[36] Hwang, C. and Yoon, K. (1981) Multiple Attribute Decision Making: Methods and Application. Springer, New York. http://dx.doi.org/10.1007/978-3-642-48318-9

[37] Abdullah, L. and Zamri, N. (2010) Ranking of the Factors Associated with Road Accidents Using Correlation Analysis and Fuzzy TOPSIS. Australian Journal of Basic and Applied Sciences, 4, 35-48.

[38] Chen, Y. and Whalley, A. (2012) Green Infrastructure: The Effects of Urban Rail Transit on Air Quality. American Economic Journal: Economic Policy, 4, 58-97.

http://dx.doi.org/10.1257/pol.4.1.58

\section{Submit or recommend next manuscript to SCIRP and we will provide best service for you:}

Accepting pre-submission inquiries through Email, Facebook, LinkedIn, Twitter, etc.

A wide selection of journals (inclusive of 9 subjects, more than 200 journals)

Providing 24-hour high-quality service

User-friendly online submission system

Fair and swift peer-review system

Efficient typesetting and proofreading procedure

Display of the result of downloads and visits, as well as the number of cited articles

Maximum dissemination of your research work

Submit your manuscript at: http://papersubmission.scirp.org/

Or contact jtts@scirp.org 